\title{
Correlation of Clinicopathological Characteristics of Breast Carcinoma and Depression
}

\author{
Milena B Ilic ${ }^{1}$, Slobodanka Lj Mitrovic ${ }^{1, *}$, Milena S Vuletic ${ }^{1}$, Uros M Radivojcevic ${ }^{2}$, \\ Vladimir S Janjic ${ }^{3}$, Vesna D Stanković ${ }^{1}$, Radisa H Vojinovic ${ }^{4}$, Dobrivoje S Stojadinovic ${ }^{5}$,
} Branimir R Radmanovic ${ }^{3}$ and Dalibor V Jovanovic ${ }^{1}$

1 Department of Pathology, Faculty of Medical Sciences, University of Kragujevac, 34000 Kragujevac, Serbia; lena.ilic@medf.kg.ac.rs (M.B.I.); milena.vuletic@medf.kg.ac.rs (M.S.V.);

wesna.stankovic@medf.kg.ac.rs (V.D.S.); dalekg84@medf.kg.ac.rs (D.V.J.)

2 Department of Surgery, Faculty of Medical Sciences, University of Kragujevac, 34000 Kragujevac, Serbia; radivojcevicuros@medf.kg.ac.rs

3 Department of Psychiatry, Faculty of Medical Sciences, University of Kragujevac, 34000 Kragujevac, Serbia; vladadok@medf.kg.ac.rs (V.S.J.); biokg2005@medf.kg.ac.rs (B.R.R.)

4 Department of Radiology, Faculty of Medical Sciences, University of Kragujevac, 34000 Kragujevac, Serbia; rhvojinovic@medf.kg.ac.rs

5 Department of Anatomy, Faculty of Medical Sciences, University of Kragujevac, 34000 Kragujevac, Serbia; dobrivoje.stojadinovic@medf.kg.ac.rs

* Correspondence: smitrovic@medf.kg.ac.rs, Tel.: +381658080877

Received: 29 July 2019; Accepted: 10 September 2019; Published: 12 September 2019

check for updates

\begin{abstract}
The prevalence of depression among women with breast cancer (BC) is extremely variable in research studies. The aim of this study was to determine the prevalence of depressive disorder in women suffering from BC as well as to examine its relationship with clinical-pathological and immunophenotypic characteristics of BC. The study included 194 patients with BC who were diagnosed with the disease between 2009 and 2015 in the Clinical Center Kragujevac, Serbia. Pathohistological and immunohistochemical analyses was used on the material obtained after the surgical removal of breast tumors, determining all significant clinical and morphological parameters. The level of depression among the examinees confirmed that the differences in the level of depression between the histological grades were statistically significant. According to the univariate binary logistic regression, the depression of a patient correlates with the category of molecular tumor subtype/Luminal A ( $p<0.0005)$, PR expression $(p=0.050)$ and lymphatic invasion $(p=0.025)$. Multivariate binary logistic regression showed that the onset of depression associated with the present molecular subtype of the tumor of a worse prognostic character $(p=0.019)$. Depression is a common disorder in women with breast cancer. The level of depression is correlates with some of the clinicomorphological and immunophenotypic characteristics of BC.
\end{abstract}

Keywords: breast cancer; depression; clinicopathological characteristics; molecular subtype; immunohistochemistry

\section{Introduction}

Breast cancer (BC) is the most common malignant tumor in women, with 458,000 deaths and 1.7 million newly diagnosed cases annually worldwide. It is responsible for the cancer-related deaths in $20 \%$ of cases [1]. In Serbia, each day there are 13 new women diagnosed with breast cancer, and four of them do not survive this disease. Conventional BC therapy, which includes surgery, radio and chemotherapy, as well as hormone therapy, shows different success rates depending mostly on clinical and pathological characteristics. Thanks to advanced early detection procedures and more 
effective treatment, the prognosis of the disease has improved and today $89 \%$ of women survive five years from the diagnosis. Due to the increase in the survival rate of women affected by BC, the focus of researchers and clinicians has shifted to monitoring of the quality of life following the complex therapeutic protocols conducted in most cases [2].

Communication of the diagnosis and learning that one suffers from this severe illness has a great influence on the psychological and emotional field of a woman, followed by occurrence of negative and unpleasant feelings such as fear, hopelessness, guilt, despair, and a serious sense of abandonment [3]. Depression is the most common psychological disorder happening in patients with $\mathrm{BC}$ [4]. The prevalence of depression among women with $\mathrm{BC}$ is extremely variable in research studies, ranging from 1 to $56 \%$, and in some cases reaching a value close to $70 \%$ [5]. Sometimes, physical distress, the therapeutic treatment of carcinoma, and the dysfunction caused by the disease jointly make the depression more difficult to detect and treat [6].

The uncertainty related to the therapeutic procedures, physical symptoms, fear of death and relapse, change in feminine appearance, physical expression and sexuality, difficulties in carrying out everyday activities, problems in the family, as well as the lack of emotional support from close ones are sources of serious psychological suffering of a patient with BC [7].

The presence of depression in patients with $\mathrm{BC}$ contributes to reduced understanding of the problem and acceptance of the condition, as well as to the ability to overcome the difficulties during the therapeutic process. They have a serious obstacle to achieving social interaction, their suitability for therapeutic procedures is significantly reduced, and their overall quality of life is deteriorated. The psychiatric disorders present in these patients have been proven to cause pain, disturbing physical status, satisfaction, emotional and social well-being, as well as general course and outcome of the disease [7].

An extensive study assumed and proved that depression affects, to a small extent, the overall risk of developing cancer [8]. Behavioral factors have a role in the development of cancer and psychiatric disorders can occur in a patient with cancer due to various psychological factors having a neurophysiological and perceptual character. The mechanisms of interaction between depression and cancer are not known, but it is assumed that one of the possible mechanisms involves pathways of endocrine hormones (e.g., sexual hormones), which at some level can affect 5-hydroxytryptamine (5HT) signaling pathway that is important for depression [9]. This assumption makes researchers pay special attention to carcinomas that develop due to hormones, i.e., hormone-dependent carcinomas (e.g., breast cancer, prostate, endometrium, etc.).

There is a need for research to show the prevalence of depressive symptoms among women with breast cancer as well as to show how depression affects the evolution of cancer. The research studies on the problems of pharmacological and psychotherapeutic approaches in the treatment of depressive disorder in women with breast cancer are rare. There is particular interest in researching possible interactions of drugs administered during an oncological treatment and a possible use of antidepressants, with the ultimate outcome on survival. One study demonstrated a pronounced correlation between the efficiency of Tamoxifen used during the oncological treatment and the presence of depressive symptoms in women with BC [10].

Understanding depression in cancer patients can help to integrate strategies into a regular therapeutic procedure that would reduce the psychological suffering of the diseased and undoubtedly improve overall survival. This opinion is supported by the results of studies that explored a number of clinical parameters in cancer patients who showed signs of depression [11].

Little is known about the relationship between depression and clinical-pathological and immunophenotypic characteristics of $\mathrm{BC}$, as well as the possible mechanisms that could explain this interaction. In this study, we aimed to reveal the share of patients with depression among patients with BC, as well as to determine possible associations with the clinical-pathological and immunophenotypic characteristics of the tumor. 


\section{Materials and Methods}

\subsection{Study Design}

The aim of this study was to determine the prevalence of depressive disorder in women suffering from BC as well as to examine its relationship with clinical-pathological and immunophenotypic characteristics of $\mathrm{BC}$. The research was approved by the Ethics Committee of the Clinical Center, Kragujevac. This research was conducted as a clinical-experimental, retrospective-prospective study. The study included 194 patients with BC who were diagnosed with the disease between 2009 and 2015 in the Clinical Center in Kragujevac. The women involved in the study were from the region of Western Serbia and Sumadija. Inclusion criteria were: women over 18; women who had signed an informed consent to participate in the study; women who had been diagnosed with BC at least three weeks before conducting a self-assessment survey on depression; and the absence of other malignancy or an acute condition that would affect psychological well-being at the time of the interview. Exclusion criteria were: women with a history of psychiatric illness prior to BC diagnosis; and women with disseminated metastases in the brain at the time of the survey.

\subsection{Pathohistological Analysis and Immunohistochemical Method}

Standard pathohistological analysis and immunohistochemical method were used on the material obtained after the surgical removal of breast tumors (tumorectomy/mastectomy), determining all significant clinical and morphological parameters: tumor size, nodal status, histological type, mitotic index, necrosis, lymphovascular invasion, etc. After that, the immunophenotype was defined according to which BC was classified into one of the following groups: Luminal A (Lum A-, ER+, PR+, HER2-), Luminal B (Lum B-, ER+, PR+, HER2+, any level of Ki67 or ER+, PR+, HER2-, Ki67 > 14\%), HER2+ (ER-, PR-, HER2+), triple negative breast cancer (TNBC - ER-, PR-, HER2-). The immunophenotype was defined by using an immunohistochemical method involving a range of antibodies that included ER, PR, HER2, and Ki67 in all cases, as well as, if needed, a variety of different cytokeratins following the recommended protocols, using formalin-fixed, paraffin-embedded tumor samples. According to macro and micromorphological characteristics, the pathological stage of the disease was defined according to the WHO recommendations [12]. The evaluation of the immunohistochemical analysis was done by using a semi-quantitative evaluation of expression, according to well-known standards [13].

\subsection{Depression Evaluation}

The respondents were given one survey, complemented with brief instructions and information about the study. The first group of patients completed surveys before the surgery (preoperatively), the second group when they came for the pathohistological finding (7-20 days after the surgery), and the third group completed the survey after the oncological therapy (regular control). A self-assessment of depression was used (Zung scale). The questionnaires consisted of 20 questions with the option to answer with marks from 1 to 4 (1, A Little of The Time; 2, Some Of The Time; 3, Good Part Of The Time; 4 , Most Of The Time), with certain questions $(2,5,6,11,12,14,16,17,18$, and 20) in the questionnaire for depression being inversely scored $(1=4,2=3,3=2,4=1)$. The overall score implied the existence/absence of disorders in the following form: up to 40, normal range; 40-50, mild form; 50-60, moderate form; 60-70, markedform; and 70-80, severe form of depressive disorder requiring hospitalization.

\subsection{Statistical Analysis of Data}

Statistical analysis was performed using SPSS Version 19. Continuous variables were presented as mean \pm SD or median (25th percentile-75th percentile). Comparisons between two groups were analyzed by $t$ test or Mann-Whitney test. Comparisons between more than two groups were done using ANOVA or Kruskal-Wallis test. Spearman's coefficient was used to test correlations. Qualitative data were analyzed with $\chi^{2}$ test. A univariate and multivariate analysis using logistic regression 
techniques, including odds ratio (OR), was performed to determine the effects of each factor on the dependent variable (depression). Differences were considered significant at $p<0.05$.

\section{Results}

\section{General Characteristics}

Of the 194 patients who were involved in the study, the average age was $60.48 \pm 12.97$ (range from 21 to 85 ). The average time elapsed since the woman had found out that she was suffering from breast cancer until the survey was $9.67 \pm 14.08$ months. Thirty-three respondents $(17 \%)$ were from rural areas, while 161 (83\%) lived in the city. More than half of the patients completed secondary school, $64(33 \%)$ were employed, while 38 (19.6\%) were unemployed, and 92 (47.4\%) were retired. Most of them did not provide information on positive family history of significant psychiatric disorders, and half of them also had chronic illnesses.

Fifty-seven women involved in the study belonged to stage I (32.9\%), 84 (48.6\%) to stage II, 13 $(7.5 \%)$ to stage III, and 19 women (11\%) to stage IV. The most common histological type of BC, according to histopathological analysis, was invasive ductal carcinoma in 157 patients (84.9\%); 21 (11.4\%) subjects had a diagnosis of invasive lobular carcinoma, while 7 (3.8\%) were diagnosed with other histological types (Table 1).

Table 1. General characteristics of female subjects.

\begin{tabular}{|c|c|}
\hline Variable & Mean \pm SD or Frequency $(\%)$ \\
\hline Age & $60.48 \pm 12.97$ \\
\hline The time from finding out the diagnosis & $9.67 \pm 14.08$ \\
\hline $\begin{array}{l}\text { Urbanity } \\
\text { village } \\
\text { town }\end{array}$ & $\begin{array}{c}33(17 \%) \\
161(83 \%)\end{array}$ \\
\hline $\begin{array}{l}\text { Employment } \\
\text { employed } \\
\text { retired } \\
\text { unemployed }\end{array}$ & $\begin{array}{l}64(33.0 \%) \\
92(47.4 \%) \\
38(19.6 \%)\end{array}$ \\
\hline $\begin{array}{c}\text { Stage } \\
1 \\
2 \\
3 \\
4\end{array}$ & $\begin{array}{c}57(32.9) \\
84(48.6 \%) \\
13(7.5) \\
19(11.0)\end{array}$ \\
\hline $\begin{array}{c}\text { Histological type } \\
\text { ductal } \\
\text { lobular } \\
\text { the others }\end{array}$ & $\begin{array}{c}157(84.9 \%) \\
21(11.4 \%) \\
7(3.8 \%)\end{array}$ \\
\hline $\begin{array}{l}\text { Molecular subtype of breast cancer (BC) } \\
\text { Luminal A } \\
\text { Luminal B } \\
\text { HER2+ } \\
\text { TNBC }\end{array}$ & $\begin{array}{c}30(19.6 \%) \\
86(56.2 \%) \\
28(18.3 \%) \\
9(5.9 \%)\end{array}$ \\
\hline $\begin{array}{c}\text { Categories of depression } \\
\text { without depression } \\
\text { mild } \\
\text { moderate } \\
\text { marked } \\
\text { severe }\end{array}$ & $\begin{array}{c}63(32.5 \%) \\
53(27.3 \%) \\
47(24.2 \%) \\
27(13.9 \%) \\
4(2.1 \%)\end{array}$ \\
\hline
\end{tabular}


Histopathological analysis showed that $16.2 \%$ of tumors were histological grade $1,50 \%$ were histological grade 2, and 33.8\% were histological grade 3. Molecular subclassification of BC identified four subtypes: Lum A, Lum B, HER2 positive tumors, and TNBC with the distribution of the subtypes in our study of $19.6 \%, 56.2 \%, 18.3 \%$, and $5.9 \%$, respectively (Table 1 ).

Out of the 194 patients, 131 (67.5\%) showed signs of a depressive disorder, and 63 (32.5\%) did not show such signs. Among the women with signs of the disorder, 53 (27.3\%) had signs of mild, 47 (24.2\%) moderate, 27 (13.9\%) marked form, and 4 (2.1\%) severe form of disorders (Table 1$)$.

Statistical data processing showed that sociodemographic characteristics (age of the patient, city-village, employed-unemployed) were not related to the level of depression. It turned out that the time that elapsed since the diagnosis and the level of depression were in negative correlation ( $\mathrm{r}=-0.151, p=0.035)$.

The analysis of the clinical and pathological characteristics of the tumor and the level of depression among the examinees confirmed that the differences in the level of depression between the histological grades were statistically significant $(p=0.040)$. The differences in the level of depression were also significant between nuclear grades $(p=0.011)$. It was also demonstrated that the patients were more depressed when there were signs of lymphatic invasion in the tumors $(p=0.014$, Table 2$)$.

Table 2. Depression level according to clinical and pathological characteristics.

\begin{tabular}{ccc}
\hline Variable & Level of Depression (mean \pm SD) & $p$ \\
\hline Histological grade & & \\
\hline 1 & $42.35 \pm 10.43$ & 0.040 \\
2 & $48.90 \pm 11.97$ & \\
\hline Nuclear grade & $49.77 \pm 12.55$ & \\
\hline 1 & & \\
2 & $41.33 \pm 8.30$ & \\
3 & $49.55 \pm 12.04$ & \\
\hline Lymphatic invasion & $49.56 \pm 13.56$ & \\
\hline No & & \\
Yes & $43.65 \pm 11.45$ & \\
\hline Immunophenotypes & $49.03 \pm 11.85$ & \\
\hline Luminal A & & $<0.0005$ \\
Luminal B & $39.80 \pm 8.47$ & \\
HER2 & $48.70 \pm 11.88$ & \\
TNBC & $49.68 \pm 13.64$ & \\
\hline Ki67 & $65.33 \pm 6.60$ & \\
\hline low & & \\
medium & $39.32 \pm 8.52$ & \\
high & $49.18 \pm 10.14$ & \\
\hline
\end{tabular}

Statistical analysis of the data obtained through our research showed that there were differences in the level of depression depending on the whether a patient belonged to certain categories. Namely, the difference in the mean values of the level of depression between histological grade 1 and grade 3 was statistically significant ( $p=0.046$, Figure 1$)$. The differences in the level of depression were also significant between nuclear grades 1 and 3 ( $p=0.015$, Figure 2$)$. 


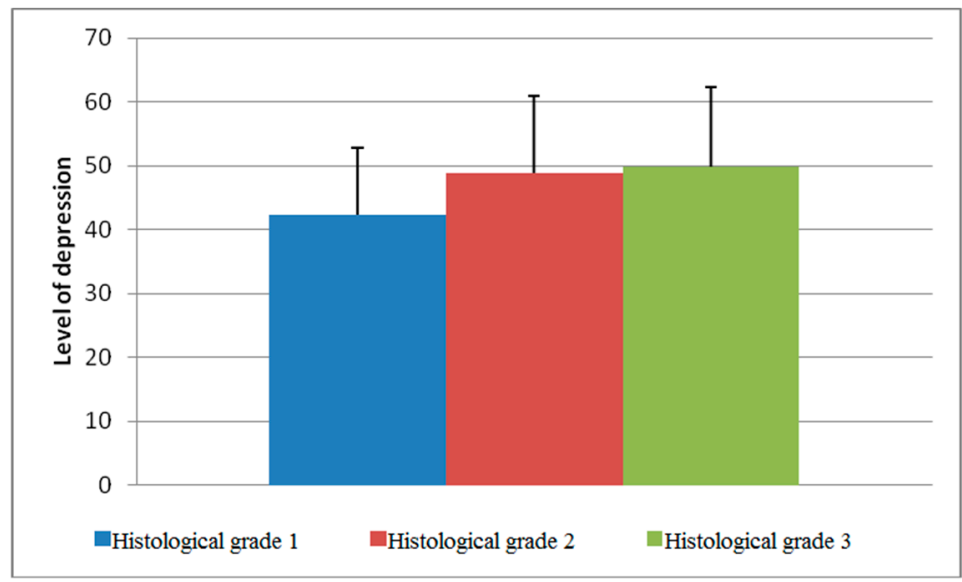

Figure 1. The difference between the mean values of the level of depression between the histological grades.

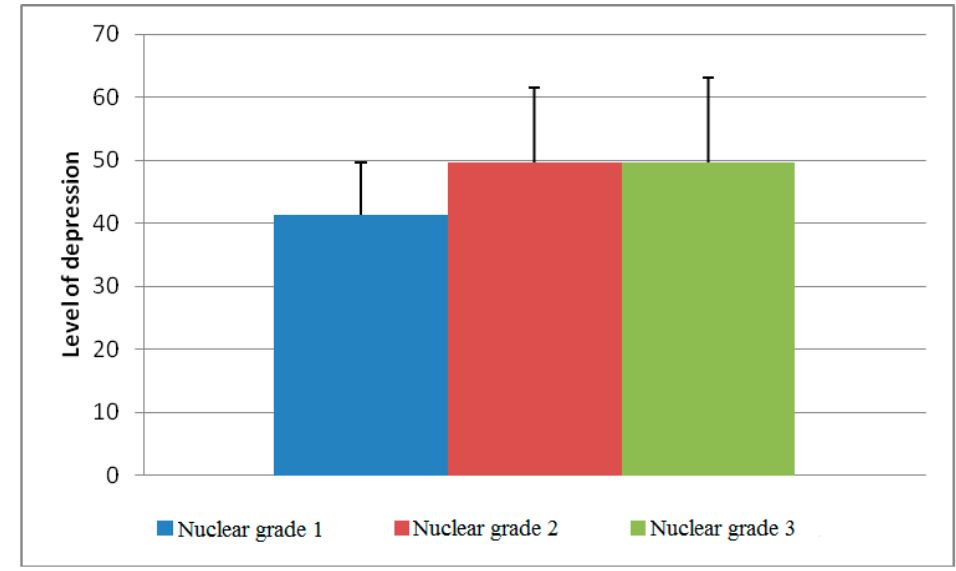

Figure 2. The difference between the mean values of the level of depression between the nuclear grades.

In addition to the correlation between the level of depression and the histological and nuclear grades, a positive correlation between the levels of depression and positive nodal status was observed $(\mathrm{r}=0.147, p=0.041)$ as well.

The difference in depression levels was shown to be significant among all BC immunophenotypes $(p<0.0005)$, except between Luminal B and HER2 positive subtypes. The mean depression level of a patient with a tumor belonging to the Luminal A subtype was $39.80 \pm 8.47$, for Luminal B $48.70 \pm$ 11.88, for HER2 positive $49.68 \pm 13.64$, and for TNBC $65.33 \pm 6.60$ (Figure 3).

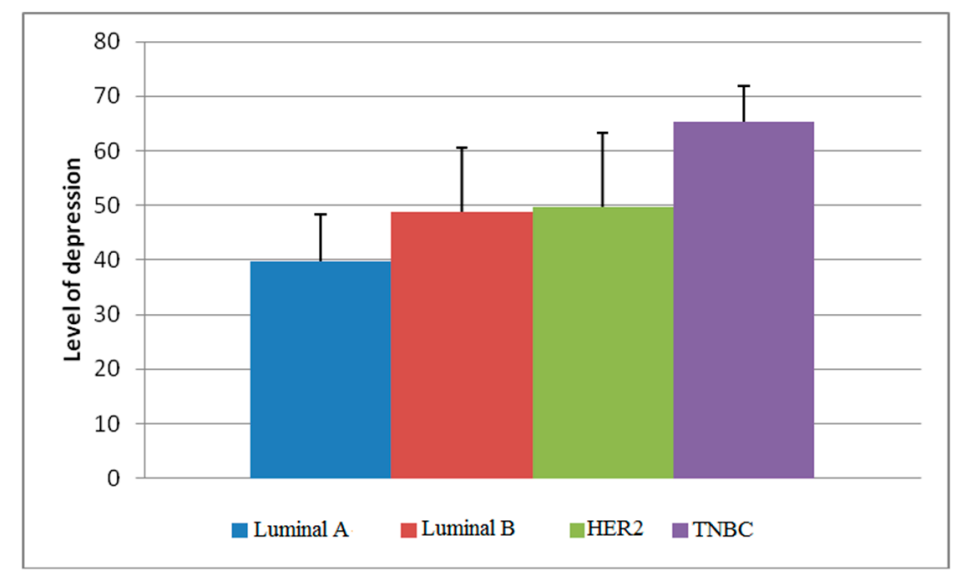

Figure 3. The difference between the mean values of the level of depression between the immunophenotypes. 
Furthermore, the differences in the level of depression and the proliferative index measured through the Ki67 expression were statistically significant $(p<0.0005)$. The patients whose tumors showed a high immunohistochemical index of proliferation were significantly more depressed than those whose tumors showed lower Ki67 expression (Figure 4).

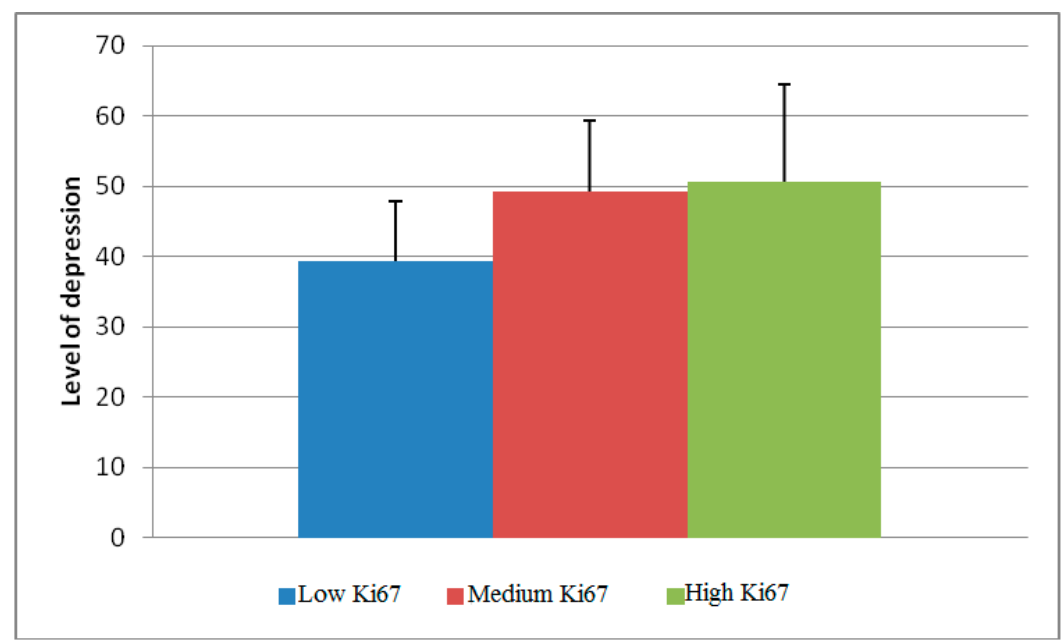

Figure 4. The difference between the mean values of the level of depression between the Ki67 categories.

Our study shows that levels of depression and receptor expression for ER were in negative correlation $(r=-0.269, p<0.0005)$. Specifically, the higher the level of depression, the lower the estrogen (Figure 5).

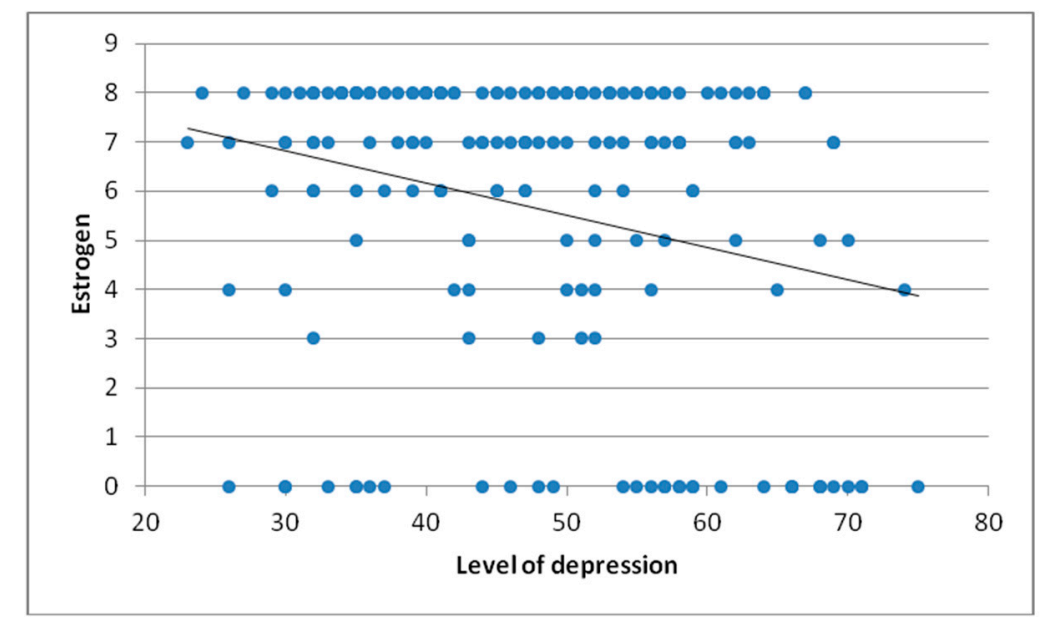

Figure 5. Correlation between level of depression and estrogen.

The patients were divided into two groups according to the level of depression: those with a depression level greater than or equal to 40 (depressed) and those with a depression level of less than 40 (non-depressed). The levels of receptor expression for ER in tumors differed significantly between depressed and non-depressed patients ( $p=0.023$, Figure 6) 


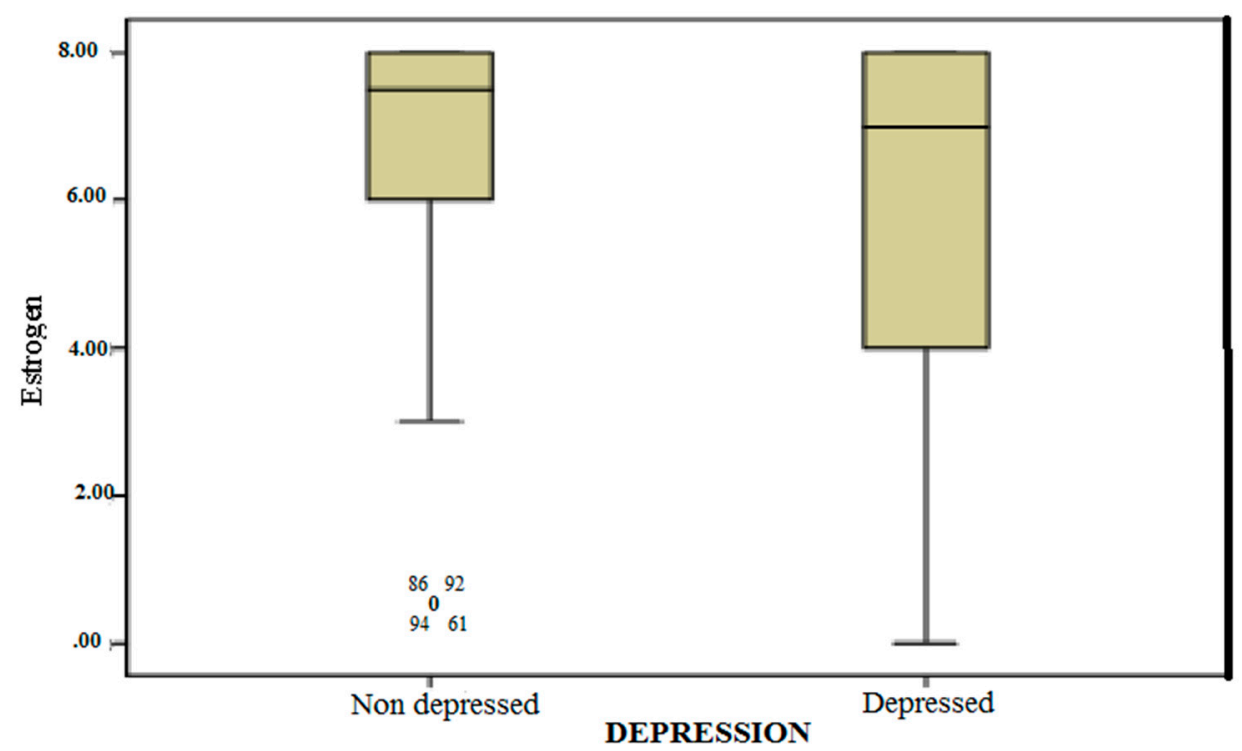

Figure 6. Correlation between level of depression and estrogen.

Depression was also associated with tumors showing signs of lymphatic invasion $(r=0.014)$. The patients whose tumors had lymphatic invasion exhibited depression in $73.1 \%$ of cases, while the percentage in tumors without lymphatic invasion was 53.5\%. Depression was also associated with a molecular tumor subtype $(p<0.0005)$. The smallest percentage of depressed patients $(36.7 \%)$ belonged to the category of Luminal A subtype, while $100 \%$ of the TNBC tumor patients were depressed. Depression also correlates with the the expression of the Ki67 proliferation index $(p<0.0005)$. The smallest percentage of depressed patients was in the category of tumors with low Ki67 (Table 3).

Table 3. Characteristics associated with depression expressed as medium.

\begin{tabular}{cccc}
\hline Variable & Non-Depressed & Depressed & $p$ \\
\hline Estrogen & $7.50(6.00-8.00) *$ & $7.00(4.00-8.00) *$ & 0.023 \\
Progesterone & $6.00(1.50-7.50) *$ & $4.00(0.00-7.00) *$ & 0.047 \\
\hline Lymphatic invasion & & & \\
\hline No & $20(46.5 \%)$ & $23(53.5 \%)$ & 0.039 \\
Yes & $25(26.9$ & $68(73.1 \%)$ & \\
\hline Immunophenotypes & & & \\
\hline Luminal A & $19(63.3 \%)$ & $11(36.7 \%)$ & \\
Luminal B & $22(25.6 \%)$ & $64(74.4 \%)$ & \\
HER2 & $9(32.1 \%)$ & $19(67.9 \%)$ & \\
TNBC & $0(0.0 \%)$ & & \\
\hline Ki67 & & $9(100.0 \%)$ & \\
\hline low & $19(67.9 \%)$ & $30(88.2 \%)$ & \\
medium & $4(11.8 \%)$ & $53(68.8 \%)$ & \\
high & $24(31.2 \%)$ & & \\
\hline
\end{tabular}

According to the univariate binary logistic regression, the depression of a patient depended on the category of molecular tumor subtype/Luminal A $(p<0.0005)$, PR expression $(p=0.050)$, and lymphatic invasion $(p=0.025)$. Multivariate binary logistic regression showed that the onset of depression depended on the present molecular subtype of the tumor of a worse prognostic character (Luminal B, HER2,+ TNBC), $(p=0.019$, Table 4$)$. See other results of binary logistic regression in the same table. 
Table 4. Binary logistic regression.

\begin{tabular}{ccccc}
\hline Variable & Univariate Regression & \multicolumn{2}{c}{ Multivariate Regression } \\
\hline Age & $1.026(1.103-1.051)$ & 0.029 & Odds Ratio & $p$ \\
\hline Desmoplasia & $2.543(1.400-4.616)$ & 0.002 & $2.452(1.233-4.876)$ & 0.011 \\
\hline Progesterone & $0.906(0.821-1.000)$ & 0.050 & & 0.007 \\
\hline Estrogen & $0.893(0.795-1.002)$ & 0.053 & & \\
\hline Non luminal A & $5.126(2.128-11.955)$ & $<0.0005$ & & \\
\hline Lymphatic invasion & $2.365(1.112-5.030)$ & 0.025 & & \\
\hline Histological type & $0.600(0.325-1.109)$ & 0.103 & & \\
\hline Histological grade & $1.498(0.887-2.527)$ & 0.130 & & \\
\hline Nuclear grade & $1.351(0.779-2.344)$ & 0.284 & \\
\hline Ki67 & $1.784(1.146-2.777)$ & 0.010 & \\
\hline Perineural invasion & $1.292(0.622-2.684)$ & 0.492 & \\
\hline Vascular invasion & $1.561(0.721-3.378)$ & 0.258 & \\
\hline In situ & $0.745(0.401-1.381)$ & 0.350 & \\
\hline HER2 & $1.376(0.664-2.853)$ & 0.391 & \\
\hline T & $1.226(0.850-1.768)$ & 0.276 & \\
\hline $\mathrm{N}$ & $1.373(0.916-2.058)$ & 0.124 & \\
\hline $\mathrm{M}$ & $0.630(0.137-2.904)$ & 0.553 & \\
\hline
\end{tabular}

\section{Discussion}

A number of studies have been conducted on the topic of cancer and depression, and the data obtained show very contradictory findings related to the relationship between these two categories. The first major research studies on this topic began in 1980, followed by a single meta-analysis conducted in 1994, which showed that the odds ratio between depression and subsequent cancer development was 1.14, thus showing that this relationship was small and statistically insignificant.

Depending on the scales for measuring depression used in studies, the percentage of patients with depression is extremely variable, from an extremely low value of $1 \%$, to over $50 \%$ in some studies [5]. The reason for such a significant difference in the results obtained can mostly be explained by the choice of the research type and its design, and partially by the choice of the way in which depression levels were measured. Nevertheless, it has been proven that depressive disorder is 2-3 times more common in patients with cancer than in the general population [14]. Frequent comorbidities of cancer and depression have led to numerous studies examining the molecular basis of these disorders, with a view to more clearly understanding the mechanisms of these disorders and to discovering potential sites for therapeutic action. These studies revealed a number of substances that have been proven to influence tumor cell behavior and the psychological status of patients. One of the tested substances is substance $\mathrm{P}(\mathrm{SP})$, present in both nerve and many other tissues. It exerts its effect through the NK receptor(NKR), which is expressed both in the peri and intratumoral tissue and has been shown to influence the modulation of tumor cells (proliferation, progression, angiogenesis, metastasis, etc.) [15]. SP and NKR are known to be widespread in the central nervous system, predominantly in structures of the limbic system, such as the thalamus and amygdala, and are thought to have an important influence in integrating the emotional response to stress, so that the development of depression itself may be associated with alterations to the SP/NKR system, as the level of SP in depressive disorders is significantly elevated [16]. It has also been suggested that proinflammatory cytokines released in the immune response and inflammation may contribute to the high rate of depression in cancer patients. 
$\mathrm{Li}$ and co-authors examined the association of a number of proinflammatory and anti-inflammatory cytokines with depression in breast cancer patients [17]. Most of these studies were not designed to show the direction of cause-and-effect relationships between depression and cancer.

Dealing with the diagnosis of a disease that seriously threatens to endanger one's life, such as cancer, is almost always followed by a marked stress response, with the appearance of negative and unpleasant feelings such as fear, hopelessness, guilt, despair, and a serious sense of abandonment [3]. Furthermore, the diagnosis and treatment of cancer are associated with numerous acute and chronic stressors that can and certainly do affect the quality of life. It is therefore not surprising that depression is one of the most common disorders diagnosed in people with cancer, with almost $1 / 3$ of patients experiencing depression symptoms at the moment of diagnosis, while $1 / 4$ have symptoms sufficient to meet the criteria for setting up a clinical diagnosis severe depression [18].

The uncertainty related to the therapeutic procedures, physical symptoms, fear of death and relapse, change in feminine appearance, physical expression and sexuality, difficulties in carrying out everyday activities, problems in the family, as well as the lack of emotional support from close ones are sources of serious psychological suffering of a patient with BC [7]. Women find the breast to be very important: it is a symbol of femininity and sexuality, so surgical removal due to cancer is associated with a sense of loss of sexuality, attraction, and maternity, as well as a negative impact on the overall physical appearance [19]. One study showed that depression was associated with a higher level of anxiety, lower self-esteem, and a distorted image of one's body expression in women with BC [2].

Prolonged and frequent therapeutic treatments and side effects of radio and chemotherapy can trigger depression in women with BC [20]. The level of anxiety is very high in younger patients and middle-aged patients receiving chemotherapy. There are simultaneous occurrences of several different disorders, such as depression, anxiety $(24 \%)$, panic (18\%), and post-traumatic stress disorder $(30 \%)$ [21]. The patients who have been diagnosed with these disorders have a longer stay in the hospital and a decrease in the quality of life after leaving the hospital [22].

A systematic literature review of the studies conducted in Iran from 2001 to 2016 showed that in all women, measured by different scales, there was at least a mild form of depression. One study showed that as many as $69.4 \%$ of women with BC displayed a form of severe depression [23]. The presence of depression in women with BC varied across different climates, cultures, and geographic locations, so in Asian countries the prevalence was 26\% [24], in India 21.5\% [25], while in Turkey $27.7 \%$ had symptoms of moderate and $19.5 \%$ of serious depression [26]. In studies conducted in the United States during 2000, 2005, 2010, and 2012, the prevalence of depression was 26\% [27], 10\% [28], 42\% [29], and $56 \%$, respectively [30]. In European countries, such as Germany, it was shown that $11 \%$ of affected women suffered from moderate depression, while $12 \%$ showed signs of severe depression [31]. Studies in Greece showed that $54.4 \%$ of women with BC experienced some form of depressive disorder [32]. In Italy, a study reported that $18 \%$ of patients showed symptoms of depression [33]. Possible causes of this kind of variance in data from these studies in different countries include differences in demographic characteristics, such as the age of subjects, their marital status, time of diagnosis of BC, type and number of therapeutic procedures [34], as well as geographical and cultural differences that certainly affect subjects' mental and psychosocial states. In our research, out of the 194 patients, 131 (67.5\%) showed signs of a depressive disorder, and $63(32.5 \%)$ did not show such signs. Among the women with signs of the disorder, 53 (27.3\%) had signs of mild, 47 (24.2\%) moderate, 27 (13.9\%) marked forms, and $4(2.1 \%)$ severe forms of disorders (Figure 2).

Previous studies, which dealt with the correlation between socio-demographic and clinical-pathological characteristics and depression, showed that the results were highly contradictory. They showed that depression was associated with age, education, and material and marital status, [31] while other studies stated that this association did not exist [35]. The result of our research showed that the association of socio-demographic characteristics (age, employment, place of residence, etc.) and depression in women with BC was not statistically significant. 
The presence and level of depression in diagnosed women is greatly influenced by the time that elapses from finding out the diagnosis of BC. Previous studies showed that the level of depression in diseased women was the highest within the first year of diagnosis. Within a period of 5 years, it was considered that depression was significantly influenced by individual factors (e.g., age, previous psychological status, lack of support from the environment) to a significantly larger extent than the disease itself or the factors associated with therapeutic procedures (e.g., the number of lymph nodes affected by metastases, tumor size, the result of biopsy, the treatment of the axillary metastasis complications) [36]. Other studies that observed patients and measured the level of disorder six times in 5 years from the moment of diagnosis showed that the depression rate was the highest in the first year (48\%) [37].Vahdadina et al. found that despite the fact that the level of anxiety and depression decreased over time, their values were $38.4 \%$ and $32.2 \%$, within 18 months, measured using the Hospital Anxiety and Depression Scale (HADS) [36]. Hopwood et al. performed measurements using the HADS scale in 211 patients with advanced carcinoma and confirmed the presence of anxiety and/or depression in $27 \%$ of them [38]. They also confirmed that 155 patients continued to show symptoms and signs of these disorders even after 1-3 months. Based on data from a study in which the level of disorder was measured before diagnosing carcinoma, then postoperatively after 1, 3, 6, and 12 months, it was demonstrated that the depression rate decreased from $40.9 \%$ to $27.8 \%$ after a year, while the symptoms could return as time passed [39].The data in our study also showed that the level of depression decreased as time elapsed from the moment of diagnosis $(r=-0.151, p=0.035)$.

According to available information, this is one of a few studies carried out on the territory of the Republic of Serbia that investigated the relationship between clinical and pathological characteristics of BC and the presence of depressive disorders in the patients. Statistical analysis of the data obtained through our study showed that differences in depression among diagnosed women exist between the following categories: histological tumor grade, especially grade 1 and $3(p=0.046)$; nuclear tumor grade (grade 1 and $3, p=0.015)$; patients with $B C$ who showed signs of lympho-vascular invasion were significantly more depressed than patients with tumors without these signs $(p=0.014)$; and patients with $\mathrm{BC}$ metastases in regional lymph nodes (axillary) showed a higher level of depression $(\mathrm{r}=0.147, p=0.041)$.

Hui et al. showed that higher-grade tumors according to TNM classification (a system to describe the amount and spread of cancer in a patient's body), as well as metastases in regional lymph nodes, were positively correlated with depression in patients with BC [40]. They also showed that the status of hormonal tumor cell receptors was related to depression, i.e., that the higher degree of expression of ER and PR corresponded to a lower degree of depression, while the proliferative index Ki67 was not correlated with depression [41]. Positive correlation of the proliferation index with the degree of depressive disorder found in our study could be a confirmation of the influence of the tumor immunophenotype group. The study by Guo et al. showed that the presence of metastases in regional lymph nodes was in a positive correlation with depression, and that depression is dependent on the status of hormonal receptors, i.e., that tumors with higher ER and PR expression levels showed higher risk of developing depression [42]. This is opposite to our results that show that the hormone status is negatively, and the proliferation index is positively correlated with the degree of depression.

Our study showed that, regarding the expression of hormonal receptors, the level of depression among the respondents differed between tumors belonging to different molecular subtypes. The differences in depression were observed between all subgroups, except between the subtype Luminal B and HER2 positive, with the lowest degree of depression being exhibited by the patients with Luminal A subtype tumor and the highest in TNBC. The results obtained are just another confirmation of the existence of the relationship between depression and the clinical and pathological characteristics of breast cancer, but molecular mechanisms, as well as the cause-and-effect direction of this relationship remain unknown.

In addition to a large number of studies that have dealt with the problem of depression in women with BC, and a large number of contrary results, it remains unclear whether depression has a direct effect on survival or whether the fact that depressed people reject proposed therapeutic procedures is a 
consequence [43]. In some studies, which investigated the relationship between depression and gastric cancer, it was found that reactive oxygen radicals could be a potential link [42]. Furthermore, extensive research by Munjoz et al. provide a detailed presentation of the molecular aspect of the substance $\mathrm{P} /$ receptor for Neurokinin complex (SP/NKR) on the progression of breast cancer and the possibility of use of drugs that block receptors with expecting positive effects on the prognosis of the disease. At the same time, this complex SP/NKR is also present in depressive disorders, and therefore the relationship and interaction of depression and carcinoma could be explained in this way [44].

\section{Conclusions}

Depression is a common disorder in women with breast cancer. The level of depression is correlates with some of the clinicomorphological and immunophenotypic characteristics of BC. The exact mechanism of interaction between depression and carcinoma remain to be explained as the topic of future studies, in order to open the way for new cancer treatment strategies to better control the disease and improve overall survival.

Author Contributions: M.B.I.: wrote the manuscript; S.L.M., V.D.S., D.V.J.: performed the pathohistological analysis and drafting of the manuscript; M.S.V., U.M.R., V.S.J.: made PubMed research and assisted in the writing of the manuscript; D.S.S., R.H.V., B.R.R.: evaluated critically the manuscript. All authors read and approved the final manuscript.

Funding: This research received no external funding.

Acknowledgments: The authors wish to thank all the women who agreed to participate in the research and thus enable its realization and give a huge contribution to science and a better understanding of this complex problem, without which there are no advancements in the results of treatment.

Conflicts of Interest: The authors declare no conflict of interest related to this work.

\section{References}

1. Xiao, Y.; Ke, Y.; Wu, S.; Huang, S.; Li, S.; Lv, Z.; Yeoh, E.; Lao, X.; Wong, S.; Kim, J.H.; et al. Association between whole grain intake and breast cancer risk: A systematic review and meta-analysis of observational studies. Nutr. J. 2018, 17, 87. [CrossRef] [PubMed]

2. Ju, H.B.; Kang, E.C.; Jeon, D.W.; Kim, T.H.; Moon, J.J.; Kim, S.J.; Choi, J.-M.; Jung, D.-U. Associations Among Plasma Stress Markers and Symptoms of Anxiety and Depression in Patients with Breast Cancer Following Surgery. Psychiatry Investig. 2018, 15, 133-140. [CrossRef] [PubMed]

3. Tavoli, A.; Mohagheghi, M.A.; Montazeri, A.; Roshan, R.; Tavoli, Z.; Omidvari, S. Anxiety and depression in patients with gastrointestinal cancer: Does knowledge of cancer diagnosis matter? BMC Gastroenterol. 2007, 7, 28. [CrossRef] [PubMed]

4. Tojal, C.; Costa, R. Depressive symptoms and mental adjustment in women with breast cancer. Psychooncology 2015, 24, 1060-1065. [CrossRef] [PubMed]

5. Zainal, N.Z.; Nik-Jaafar, N.R.; Baharudin, A.; Sabki, Z.A.; Ng, C.G. Prevalence of Depression in Breast Cancer Survivors: A Systematic Review of Observational Studies. Asian Pac. J. Cancer Prev. 2013, 14, 2649-2656. [CrossRef] [PubMed]

6. Fann, J.R.; Thomas-Rich, A.M.; Katon, W.J.; Cowley, D.; Pepping, M.; Mc-Gregor, B.A.; Gralow, J. Major depression after breast cancer: A review of epidemiology and treatment. Gen. Hosp. Psychiatry 2008, 30, 112-126. [CrossRef] [PubMed]

7. İzci, F.; İlgün, A.S.; Fındıklı, E.; Özmen, V. Psychiatric Symptoms and Psychosocial Problems in Patients with Breast Cancer. J. Breast Health 2016, 12, 94-101. [CrossRef] [PubMed]

8. Oerlemans, M.E.; van den Akker, M.; Schuurman, A.G.; Kellen, E.; Buntinx, F. A meta-analysis on depression and subsequent cancer risk. Clin. Pract. Epidemiol. Ment. Health 2007, 3, 29. [CrossRef] [PubMed]

9. Ahn, H.K.; Bae, J.H.; Ahn, H.Y.; Hwang, I.C. Risk of cancer among patients with depressive disorder: A meta-analysis and implications. Psychooncology 2016, 25, 1393-1399. [CrossRef] [PubMed]

10. Ates, O.; Soylu, C.; Babacan, T.; Sarici, F.; Kertmen, N.; Allen, D.; Sever, A.R.; Altundag, K. Assessment of psychosocial factors and distress in women having adjuvant endocrine therapy for breast cancer: The 
relationship among emotional distress and patient and treatment-related factors. Springerplus 2016, 5, 486. [CrossRef] [PubMed]

11. Jacob, L.; Hadji, P.; Albert, U.S.; Kalder, M.; Kostev, K. Impact of disease management programs on women with breast cancer in Germany. Breast Cancer Res. Treat. 2015, 153, 391-395. [CrossRef] [PubMed]

12. Brierley, J.D.; Gospodarowicz, M.K.; Wittekind, C. TNM Classification of Malignant Tumours, 8th ed.; John Wiley \& Sons, Inc.: Oxford, UK; Hoboken, NJ, USA, 2017.

13. Bancroft, J.D.; Gamble, M. Theory and Practice of Histological Techniques, 7th ed.; Churchill Livingstone: Edeinburgh, UK; London, UK; Oxford, UK; New York, NY, USA, 2012.

14. Tunel, M.; Vural, A.; Evlice, Y.E.; Tamam, L. Meme Kanserli Hastalarda Psikiyatrik Sorunlar. Arşiv Kaynak Tarama Derg. 2012, 21, 189-219.

15. Feng, F.; Yang, J.; Tong, L.; Yuan, S.; Tian, Y.; Hong, L.; Wang, W.; Zhang, H. Substance P immunoreactive nerve fibres are related to gastric cancer differentiation status and could promote proliferation and migration of gastric cancer cells. Cell Biol. Int. 2011, 35, 623-629. [CrossRef] [PubMed]

16. Munoz, M.; Covenas, R.; Esteban, F.; Redondo, M. The substance P/NK-1 receptor system: NK-1 receptor antagonists as anti-cancer drugs. J. Biosci. 2015, 40, 441-463. [CrossRef] [PubMed]

17. Li, M.; Kouzmina, E.; McCusker, M.; Rodin, D.; Boutros, P.C.; Paige, C.J.; Rodin, G. Pro- and anti-inflammatory cytokine associations with major depression in cancer patients. Psycho-Oncology 2017, 26, 2149-2156. [CrossRef] [PubMed]

18. Ho, S.S.; So, W.K.; Leung, D.Y.; Lai, E.T.; Chan, C.W. Anxiety, depression and quality of life in Chinesewomen with breastcancer during and aftertreatment: A comparativeevaluation. Eur. J. Oncol. Nurs. 2013, 17, 877-882. [CrossRef] [PubMed]

19. Rezaei, M.; Elyasi, F.; Janbabai, G.; Moosazadeh, M.; Hamzehgardeshi, Z. Factors Influencing Body Image in Women with Breast Cancer: A Comprehensive Literature Review. Iran. Red Crescent Med. J. 2016, 18, e39465. [CrossRef] [PubMed]

20. Bhattacharyya, S.; Bhattacherjee, S.; Mandal, T.; Das, D.K. Depression in cancer patients undergoing chemotherapy in a tertiary care hospital of North Bengal, India. Indian J. Public Health 2017, 61, 14-18. [CrossRef] [PubMed]

21. Kadan-Lottick, N.S.; Vanderwerker, L.C.; Bkock, S.D.; Zhang, B.; Prigerson, H.G. Psychiatric disorders and mental health service use in patients with advanced cancer. Cancer 2005, 104, 2872-2881. [CrossRef]

22. Karakoyun-Celik, O.; Gorken, I.; Sahin, S.; Orcin, E.; Alanyali, H.; Kinay, M. Depression and anxiety levels in woman under follow-up for breast cancer: Relationship to coping with cancer and quality of life. Med. Oncol. 2010, 27, 108-113. [CrossRef]

23. Shakeri, J.; Golshani, S.; Jalilian, E.; Farnia, V.; Nooripour, R.; Alikhani, M.; Kianoosh, Y. Studying the amount of depression and its role in predicting the quality of life of women with breast cancer. Asian Pac. J. Cancer Prev. 2016, 17, 643-646. [CrossRef] [PubMed]

24. Chen, X.; Lu, W.; Zheng, Y.; Gu, K.; Chen, Z.; Zheng, W.; Shu, X.O. Exercise, tea consumption, and depression among breast cancer survivors. J. Clin. Oncol. 2010, 28, 991-998. [CrossRef] [PubMed]

25. Purkayastha, D.; Venkateswaran, C.; Nayar, K.; Unnikrishnan, U.G. Prevalence of depression in breast cancer patients and its association with their quality of life: A cross-sectional observational study. Indian J. Palliat. Care 2017, 23, 268-273. [PubMed]

26. Bener, A.; Alsulaiman, R.; Doodson, L.; Agathangelou, T. Depression, hopelessness and social support among breast cancer patients: In highly endogamous population. Asian Pac. J. Cancer Prev. 2017, 18, 1889-1896. [PubMed]

27. Broeckel, J.A.; Jacobsen, P.B.; Balducci, L.; Horton, J.; Lyman, G.H. Quality of life after adjuvant chemotherapy for breast cancer. Breast Cancer Res. Treat. 2000, 62, 141-150. [CrossRef] [PubMed]

28. Speer, J.J.; Hillenberg, B.; Sugrue, D.P.; Blacker, C.; Kresge, C.L.; Decker, V.B.; Zakalik, D.; Decker, D.A. Study of sexual functioning determinants in breast cancer survivors. Breast J. 2005, 11, 440-447. [CrossRef]

29. Christie, K.M.; Meyerowitz, B.E.; Maly, R.C. Depression and sexual adjustment following breast cancer in low-income hispanic and non-hispanic white women. Psychooncology 2010, 19, 1069-1077. [CrossRef]

30. Begovic-Juhant, A.; Chmielewski, A.; Iwuagwu, S.; Chapman, L.A. Impact of body image on depression and quality of life among women with breast cancer. J. Psychosoc. Oncol. 2012, 30, 446-460. [CrossRef] 
31. Mehnert, A.; Koch, U. Psychological comorbidity and health-related quality of life and its association with awareness, utilization, and need for psychosocial support in a cancer register-based sample of long-term breast cancer survivors. J. Psychosom. Res. 2008, 64, 383-391. [CrossRef]

32. Fradelos, E.C.; Papathanasiou, I.V.; Veneti, A.; Daglas, A.; Christodoulou, E.; Zyga, S.; Kourakos, M. Psychological distress and resilience in women diagnosed with breast cancer in Greece. Asian Pac. J. Cancer Prev. 2017, 18, 2545-2550.

33. Pumo, V.; Milone, G.; Iacono, M.; Giuliano, S.R.; Di Mari, A.; Lopiano, C.; Bordonaro, S.; Tralongo, P. Psychological and sexual disorders in long-term breast cancer survivors. Cancer Manag. Res. 2012, 4, 61-65. [PubMed]

34. Rajabizadeh, G.; Mansoori, S.M.; Shakibi, M.R.; Ramazani, M.R. Determination of factors related to depression in cancer patients of the oncology ward in Kerman. J. Kerman Univ. Med. Sci. 2005, 12, 142-147.

35. Osborne, R.H.; Elsworth, G.R.; Hopper, J.L. Age-specific norms and determinants of anxiety and depression in 731 women with breast cancer recruited through a population-based cancer registry. Eur. J. Cancer 2003, 39, 755-762. [CrossRef]

36. Christensen, S.; Zachariae, R.; Jensen, A.B.; Michael Vaeth, M.; Moller, S.; Ravnsbæk, J.; von der Maase, H. Prevalence and risk of depressive symptoms 3-4 months post-surgery in a nationwide cohort study of Danish women treated for early stage breast-cancer. Breast Cancer Res. Treat. 2009, 113, 339-355. [CrossRef] [PubMed]

37. Burgess, C.; Cornelius, V.; Love, S.; Graham, J.; Richards, M.; Ramirez, A. Depression and anxiety in women with early breast cancer: Five year observational cohort study. BMJ 2005, 330, 702-706. [CrossRef] [PubMed]

38. Hopwood, P.; Howell, A.; Maguire, P. Psychiatric morbidity in patients with advanced cancer of the breast: Prevalence measured by two self-rating questionnaires. Br. J. Cancer 1991, 64, 349-352. [CrossRef] [PubMed]

39. Den Oudsten, B.L.; Van Heck, G.L.; Van der Steeg, A.F.; Roukema, J.A.; De Vries, J. The Whoqol-100 has good psychometric properties in breast cancer patients. J. Clin. Epidemiol. 2009, 62, 195-205. [CrossRef] [PubMed]

40. Hui, L.; Huang, T.; Lian, J.; Zhou, F.; Gao, C.; Lin, Y.; Nan, K.; Li, Z.; Wei, Y. Potential prognostic value of clinical characteristics, hormone status and major depressive disorder in breast cancer. Future Oncol. 2017, 13, 1493-1503. [CrossRef] [PubMed]

41. Guo, X.; Xu, J.; Ying, E.; Yu, Z.; Sun, T. Correlation between hormone receptor status and depressive symptoms in patients with metastatic breast cancer. Oncotarget 2017, 8, 50774-50781. [CrossRef] [PubMed]

42. Kishan, A.U.; Wang, P.C.; Sharif, J.; Kupelian, P.A.; Steinberg, M.L.; McCloskey, S.A. Clinical indicators of psychosocial distress predict for acute radiation-induced fatigue in patients receiving adjuvant radiation therapy for breast cancer: An analysis of patient-reported outcomes. Int. J. Radiat. Oncol. Biol. Phys. 2016, 95, 946-955. [CrossRef] [PubMed]

43. Huang, T.; Zhou, F.; Wang-Johanning, F.; Nan, K.; Wei, Y. Depression accelerates the development of gastric cancer through reactive oxygen species-activated ABL1 (Review). Oncol. Rep. 2016, 36, 2435-2443. [CrossRef] [PubMed]

44. Muñoz, M.; González-Ortega, A.; Salinas-Martín, M.V.; Carranza, A.; Garcia-Recio, S.; Almendro, V.; Coveñas, R. The neurokinin-1 receptor antagonist aprepitant is a promising candidate for the treatment of breast cancer. Int. J. Oncol. 2014, 45, 1658-1672. [CrossRef] [PubMed]

(C) 2019 by the authors. Licensee MDPI, Basel, Switzerland. This article is an open access article distributed under the terms and conditions of the Creative Commons Attribution (CC BY) license (http://creativecommons.org/licenses/by/4.0/). 